\title{
ENTRE O LEMBRAR E O ESQUECER: REFLEXÕES SOBRE A MEMÓRIA E O ESQUECIMENTO A PARTIR DE NIETZSCHE E BERGSON
}

\author{
Ludymylla Maria Gomes de Lucena ${ }^{1}$ \\ Universidade Federal do Pará (UFPA) \\ Instituto Federal de Educação, Ciência e Tecnologia do Pará (IFPA) \\ https://orcid.org/0000-0002-3221-0972 \\ E-mail: ludymyllalucena@gmail.com
}

\section{RESUMO:}

Esse trabalho tem como objetivo pôr em evidência o jogo contínuo e a relação paradoxal que se estabelece entre a memória e o esquecimento a partir das contribuições de Friedrich Nietzsche e Henri Bergson. Seguiremos a hipótese de que a origem da memória e da consciência em Nietzsche em muito se aproxima daquela feita por Bergson em Matéria e Memória. Tentarei expor como a memória em Bergson surge no intervalo entra a ação e a reação, no momento em que o homem hesita, organiza e seleciona o movimento novo. O mesmo movimento de hesitação acontece em Nietzsche, quando o homem abandona o reino "animalesco" do instante e passa a calcular e planejar os seus atos. Nesse interim em que o homem adquire a capacidade memorativa e se distancia dos animais instintivos, o esquecimento passa a ter uma importância vital, segundo Nietzsche, visto que um excesso de memória pode ressentir e entristecer o corpo. Já em Bergson, o mecanismo cerebral - um órgão de atenção à vida - também ocupa um lugar de destaque, a partir do momento em que afasta temporariamente a totalidade das lembranças (não úteis), e permite que apenas algumas delas se tornem conscientes (as úteis). Para tanto, observaremos que o que está por trás desse jogo infinito entre a memória e o esquecimento é a manutenção de um corpo saudável que não se perca nos excessos - de lembrar demais ou esquecer de tudo. Um corpo que saiba lembrar, mas também esquecer para conseguir viver.

PALAVRAS-CHAVE: Memória; Esquecimento; Corpo.

\section{BETWEEN REMEMBERING AND FORGETTING: REFLECTIONS ON MEMORY AND FORGETFULNESS FROM NIETZSCHE AND BERGSON}

\begin{abstract}
:
This work aims to highlight the continuous game and the paradoxical relationship established between memory and forgetfulness based on the contributions of Friedrich Nietzsche and Henri Bergson. We will follow the hypothesis that the origin of memory and consciousness in Nietzsche is very close to that made by Bergson in Matter and Memory. I will try to expose how memory in Bergson arises in the interval between action and reaction, at the moment when man hesitates, organizes and selects the new movement. The same hesitation movement occurs in Nietzsche, when man abandons the "animalistic" realm of the instant and begins to calculate and plan his actions. In the meantime, when man acquires the capacity to remember and distances himself from the instinctive animals, forgetfulness becomes vitally important, according to Nietzsche, since an excess of memory can resent and sadden the body. In Bergson, on the other hand, the brain mechanism - an organ of attention to life - also occupies a prominent place, from the moment it temporarily removes the totality of (non-useful) memories, and allows only some of them to become conscious (the useful ones). To this end, we will observe that what is behind this infinite game between memory and forgetfulness is the maintenance of a healthy body that does not get lost in excesses - of remembering too much or forgetting everything. A body that knows how to remember, but also how to forget in order to live.
\end{abstract}

KEYWORDS: Memory; Forgetfulness; Body.

1 Doutorando(a) em Artes na Universidade Federal do Pará (UFPA), Belem - PA, Brasil. Professor(a) do Instituto Federal de Educação, Ciência e Tecnologia do Pará (IFPA), Belém - PA, Brasil.

LUCENA, Ludymylla Maria Gomes de. Entre o lembrar e o esquecer: reflexões sobre a memória e o esquecimento a partir de Nietzsche e Bergson. Griot : Revista de Filosofia, Amargosa - BA, v.22 n.1, p.85-94, fevereiro, 2022. 


\title{
Considerações iniciais
}

\author{
Estive doente? Estou curado? \\ E quem foi meu médico? \\ Esqueci-me de tudo isso! \\ Só agora acredito que você está curado: \\ Pois só é são, quem se esqueceu. \\ Nietzsche, Gaia Ciência
}

Nas últimas décadas do século XX houve uma grande preocupação com a questão da memória. De acordo com o diagnóstico de Jeanne-Marie Gagnebin “assistimos a um boom de estudos sobre memória, desmemoria, resgate, tradições" (2006, p. 97). "Boom de memória" que se concretizou também a partir do florescimento dos julgamentos, das comissões de verdade, da criação de espaços de memória, de museus e de arquivos com acervos públicos, etc. Também observamos uma expansão dos trabalhos artísticos em torno da memória, no qual encontramos artistas que praticam uma nova "arte da memória", seja no cinema, seja nas artes visuais, seja na literatura. Ainda segundo Gagnebin (2006), cuidar da memória não se configura apenas num interesse de estudo, seja para a história, seja para a filosofia. Cuidar da memória é também uma tarefa, um dever ético. Esse dever consiste em preservar o passado, em salvar o desaparecido, resgatar, como se diz, tradições, vidas, falas e imagens.

Todavia, não podemos falar do dever ético que é lembrar, do papel importante que a arte tem nesse contexto, sem mencionar o esquecimento. Lembrar é também esquecer, ou seja, como diria Seligmann-Silva "a memória só existe ao lado do esquecimento: um complementa e alimenta o outro, um é o fundo sobre o qual o outro se insere" (2003, p. 53). Memória e esquecimento como conceitos intrínsecos e complementares - e nunca antagônicos. Ou como diria Susan Suleiman (2019, p. 283), “uma reflexão sobre a memória conduz, inevitavelmente, ao esquecimento [...]. $\mathrm{O}$ esquecimento é o agente ativo da formação das memórias; tal como o mar que esculpe a terra que o rodeia, o esquecimento dá às memórias a sua forma e o seu relevo".

Também Nietzsche (2013), na segunda dissertação da Genealogia da Moral, salienta a importância do esquecimento. Uma das hipóteses que ele segue é de que nenhuma ação é possível no presente sem algum esquecimento do passado. Esquecer então seria fundamental para assegurar um corpo saudável, não ressentido, não melancólico, não nostálgico. Já Bergson (2010), em alguns trechos de Matéria e Memória, reconhece no mecanismo cerebral uma importante função no processo evolutivo. É ele, o cérebro - instrumento de ação - que favorece o equilíbrio entre a memória e o esquecimento ao permitir que apenas uma pequena parte da totalidade de nossas lembranças - as úteis no momento - se tornem conscientes. Como uma torneira ou válvula de barragem, tal mecanismo deixaria que apenas uma pequena quantidade de água passasse, enquanto todo o gigantesco reservatório ou caixa d’agua se conservaria.

\footnotetext{
${ }^{2}$ No século XX os trabalhos artísticos em torno da representação da memória se expandem, seja no cinema (Andrei Tarkovsky, Alain Resnais, Chris Marker, Claude Lanzmann), seja nas artes visuais (Rosangela Rennó, Anselm Kiefer, Joseph Beuys). Só para mencionar alguns nomes. De acordo com Assmann (2011, p. 385), essa fascinação pela memória continua a se desenvolver: "Anselm Kiefer, Sigrid Sigurdsson e Anne e Patrick Poirier. Todos eles tomam o tema da memória como ponto central de seu trabalho artístico ou, dizendo de outra maneira, com eles a arte se torna a mídia última e singular da memória dentro de um mundo que se livrou dessa memória. Naturalmente não foram só eles que fizeram isso: esses artistas são citados aqui como exemplos de como a arte em geral se direcionou para o tema da memória, começando nos anos 1970 e se tornando dominante nos anos 1980".
} 
Esse trabalho tem como objetivo pôr em evidência o jogo contínuo entre a memória e o esquecimento a partir da leitura dos dois filósofos mencionados acima: Nietzsche e Bergson. Em Nietzsche daremos foco a dois textos: a segunda dissertação da Genealogia da moral e Sobre a utilidade e a desvantagem da história para a vida. Em evidência estarão suas formulações sobre os conceitos de esquecimento, digestão, saúde, etc. Já em Bergson Matéria e Memória estará em foco e os conceitos de memória, corpo, percepção, cérebro estarão em destaque. Seguiremos a hipótese de que a origem da memória e da consciência em Nietzsche em muito se aproxima daquela feita por Bergson. Para tanto, observaremos que o que está por trás desse jogo infinito entre a memória e o esquecimento é a manutenção de um corpo saudável que não se perca nos excessos - de lembrar demais ou esquecer de tudo. Um corpo que saiba lembrar, mas também esquecer para conseguir viver.

\title{
O esquecimento
}

Em Genealogia da moral, Nietzsche (2013, p. 57) reconhece o valor produtivo da capacidade de esquecer. $O$ esquecimento não seria uma via inertiae, como creem os supérfluos, mas antes um poder ativo, uma faculdade moderadora, um sinal de saúde forte, contra sua faculdade oposta, a memória. $\mathrm{O}$ animal, com sua vivência a-histórica, é necessariamente esquecido. Sem passado e sem futuro ele vive o presente, sem nada lembrar, sem nada sofrer. Diferente do animal, o homem perdeu fundamentalmente sua capacidade de esquecer, logo, perdeu também a sua felicidade. "Talvez na pré-história do homem não haja nada mais terrível do que a sua mnemotécnica" (2013, p. 60). Os momentos de felicidade do homem são sobretudo aqueles em que o tempo, passado e futuro, parecem suspensos:

\begin{abstract}
Observe o rebanho a pastar: ele nada sabe do que é o ontem e o hoje; saltita aqui e acolá, come, descansa, digere, novamente saltita, noite e dia, dia após dia. Em resumo, preso ao seu prazer e desprazer, estancado no instante, não se entristece nem se enfastia. Ver isso é difícil para o homem, que se vangloria de sua humanidade perante o animal, mas contempla enciumado a sorte deste - pois o homem apenas quer, como o animal, viver sem fastio e sem dor; mas o quer em vão, por não querer como aquele. $O$ homem pergunta ao animal: "por que nada me diz de sua sorte e apenas me fita?" $O$ animal quer responder e dizer: "acontece que eu sempre esqueço o que quero dizer" - mas já esquece essa resposta e silencia, e o homem se espanta (NIETZSCHE, 2014, p. 33).
\end{abstract}

A vida seria insuportável, impossível, terrível sem o esquecimento. Aqueles que de tudo lembram - como Irineo Funes, personagem de Borges - ou lembram muito - como Górchakov, personagem de Nostalgia (Nostalghia, 1983), filme de Tarkovski - adoecem, vivem tristes, melancólicos, nostálgicos ou ressentidos.

Em Funes, o memorioso, conto de Jorge Luís Borges, o personagem Funes, depois de uma queda de cavalo é acometido por uma doença que lhe confere uma memória infalível, monstruosa. Incapaz de esquecer qualquer coisa, Funes, de tudo lembra e "duas ou três vezes havia reconstruído um dia inteiro, não havia jamais duvidado, mas cada reconstrução havia requerido um dia inteiro" (BORGES, 2007, p. 105). Cada detalhe valia por si só e possuía o mesmo valor que todos os outros detalhes. Por tudo lembrar Funes não conseguia viver o presente.

Em Nostalgia (Nostalghia, 1983), filme de Tarkovsky, observamos o protagonista Górchakov profundamente ligado ao seu passado na Rússia, de modo que sofre devido a uma saudade forte demais e a um sentimento de deslocamento diante da sua vida atual na Itália. Górchakov sente-se

LUCENA, Ludymylla Maria Gomes de. Entre o lembrar e o esquecer: reflexões sobre a memória e o esquecimento a partir de Nietzsche e Bergson. Griot : Revista de Filosofia, Amargosa - BA, v.22 n.1, p.85-94, fevereiro, 2022. 
totalmente desorientado diante de tudo que vê, diante de todas as impressões com que é bombardeado - disso resulta uma certa incapacidade de incorporar a nova experiência do presente. A própria etimologia da palavra Nostalgia, derivada do grego é composta por Nostos (que significa lar) e Algos (que significa dor).

Logo, seria preciso, seguindo Nietzsche:

Fechar de quando em quando as portas e janelas da consciência [...]; fazer silêncio e tábua rasa na nossa consciência, a fim de que aí haja lugar para alguma coisa nova, principalmente para as funções mais nobres para governar, para prever, para pressentir; eis aqui, repito, o ofício desta faculdade ativa, desta vigilante guarda encarregada de manter a ordem psíquica, a tranquilidade, a etiqueta [...]. O homem em quem não funciona este complexo aparelho de retenção é um verdadeiro dispéptico, nunca conclui nada... (2013, p. 57-58)

Jorge Semprún, liberado de Buchenwald em 11 de abril de 1945, compôs o seu testamento sobre a sua experiência no Lager apenas em 1994. A explicação dada para esse atraso foi o esquecimento. Semprún optara pelo esquecimento. Em seu livro L'écriture ou la vie ele diz: "que não sabia de nada, que nunca soube de nada, eu voltei para a vida. Ou seja, para o esquecimento: a vida era o preço" "(SEMPRÚN apud SELIGMANN-SILVA, 2003, p. 53).

No filme $O$ homem sem passado (Mies vailla menneisyytta, 2003) do diretor finlandês Aki Kaurismaki, acompanhamos a história de um homem que acaba perdendo a memória devido a um espancamento que sofre na rua. Sem lembrar onde mora, onde trabalha e nem mesmo de seu próprio nome, vai buscando viver mesmo assim. Em um dado momento do filme descobre o endereço de sua antiga casa e retorna. Quando ali chega sente-se logo desconectado. Minutos depois, em diálogo com sua antiga esposa fica sabendo que não era feliz ali. Sua vida era sem satisfação e sem amor. E os dois estavam em processo de divórcio. Sua ex-mulher e seu marido atual temiam que o encontro fosse agressivo e cheio de ressentimentos, mas, pelo contrário, tudo se dá de forma amigável e positiva. Lujanen - nome do personagem que só descobrimos nesse momento do filme - vai então embora para sua nova vida, com sua nova namorada e seus novos amigos que fez depois que perdeu a memória.

\section{Um corpo saudável}

Um corpo saudável, segundo Nietzsche, é aquele que permite a digestão ${ }^{3}$, a transmutação das memórias. É aquele que consegue se abrir para o novo, renovando a consciência sempre de maneira ativa, não deixando que o que "foi" se cristalize como uma "pedra pesada" que não pode ser movida. Lembrar de tudo, não esquecer, manter algumas memórias estagnadas sem digestão, também é uma forma de descuidar do corpo, mantê-lo ressentido, nostálgico e triste. $\mathrm{O}$ ressentimento é justamente aquela memória petrificada que não circula. Todavia, "digerir" as memórias não implica em eliminalas da consciência, desatando os liames temporais. Isso seria uma forma de gerar uma desconexão

\footnotetext{
${ }^{3}$ Diferentes são as metáforas temporais da memória quando se fala de esquecimento. A metáfora do estômago remonta a Santo Agostinho que no século IV escreveu em suas confissões: “[...] a memória é, por assim dizer, o estômago da alma. A alegria e a tristeza são como alimento, que ora é doce, ora é amargo. Quando tais emoções são confiadas à memória, podem ser aí despertadas como num estômago, mas perdem o sabor. [...] assim como a comida, pela ruminação, sai do estômago, elas saem da memória através da lembrança" (AGOSTINHO apud ASSMANN, 2011, p. 178).
} 
entre o homem e o mundo ${ }^{4}$.

A metáfora da "digestão" dinamita a estagnação da memória na consciência, mas não a deleta. Não se trata de enviar para a lixeira as lembranças que doem ou não são mais úteis. Esquecer não é deletar, apagar o passado, transformar a consciência em uma folha em branco. É importante essa diferenciação entre o esquecimento, do qual fala Nietzsche, e um outro esquecimento com o qual devemos lutar contra, que é o esquecimento como sinônimo de apagamento, silenciamento e negação do passado que costuma ser orquestrado por alguns regimes totalitários e negacionistas, que manipulam e hierarquizam o que deve ser lembrado e o que deve ser esquecido.

O esquecimento do qual fala Nietzsche é uma espécie de guardião, de zelador da paz, do descanso, da ordem psíquica. Um esquecimento que tem uma dimensão feliz justamente por conseguir arejar a consciência, desfazendo o "peso do passado" e os "nós" da memória que nos corroem e nos impedem de viver o presente. Devemos, por isso, saber absorver o que nos é útil, e, a maior parte, esquecer, digerir, ruminar, ventilar, pois, como diria Nietzsche em Crepúsculo dos Ídolos: “Na Escola Bélica da Vida - o que não me faz morrer me torna mais forte” (1976, p. 10).

Um homem que sentisse tudo unicamente de forma histórica seria parecido com alguém que tivesse abdicado do sono [...]. Portanto, é possível viver, e até mesmo viver feliz, quase sem lembranças, como mostra o animal; mas é totalmente impossível viver sem o esquecimento. Ou, para me expressar sobre meu tema de forma mais clara: existe um grau de insônia, de ruminação, de sentido histórico, que prejudica o vivente e por fim o destrói, seja um homem, um povo ou uma cultura (NIETZSCHE, 2014, p. 36).

Daí a importância de uma vivência a-histórica que nos aproxime da nossa condição animal. A criança também compartilha em parte dessa condição. Por isso o homem se comove e sente inveja ao ver o rebanho pastar ou, de forma mais próxima, quando "vê a criança, que nada tem a negar do passado, brincando entre a cerca do passado e do futuro em uma cegueira abençoada, como se recordasse de um paraíso perdido" (NIETZSCHE, 2014, p. 34-35).

Todavia, essa proximidade que Nietzsche almeja para o homem, seja com o animal ou com a criança nunca se completa. $O$ homem é um estranho animal que possui memória, ou seja, um "bixo" memorativo e interiorizado que tem a capacidade de refletir sobre sua condição, que tem a capacidade de prometer. Bárbaros e violentos foram os métodos responsáveis por esse processo de "humanização" e "interiorização" do homem. Numerosas torturas se implementaram para que os homens lembrassem. A dor como o auxílio mais poderoso da mnemotécnica. Como Nietzsche diria em Genealogia da Moral: "Imprimi-se algo por meio de fogo para que fique na memória somente o que sempre dói” (2013, p. 60).

Diferentemente dos animais o instinto do homem se interioriza. Ele titubeia antes de agir. Volta-se para dentro. Calcula, pensa e só depois age. Mantêm-se sempre atento ao passado e ao futuro. Lembrando e ruminando sempre sobre o que acontece. O homem abandona o reino "animalesco" do instante, da espontaneidade, do imediato e passa a hesitar, a controlar seus instintos. Podemos afirmar que a origem da memória e da consciência em Nietzsche em muito se aproxima daquela feita por Bergson em Matéria e Memória. A memória aparece para Bergson, diria Guéron (2011, p. 136): "no momento em que adiamos e voltamos para dentro o que seria uma reação imediata

\footnotetext{
${ }^{4}$ Essa ideia aparece em Esculpir o tempo, quando Tarkovski (1990, p. 65) afirma que "privado de memória, o homem torna-se prisioneiro de uma existência ilusória; ao ficar à margem do tempo, ele é incapaz de compreender os elos que o ligam ao mundo exterior - em outras palavras, vê-se condenado à loucura".
} 
a uma ação que sofremos de fora. Também em Nietzsche a origem da memória - da memória e da consciência - é fruto de um adiamento: o adiamento de um impulso instintivo que interiorizamos".

\section{A memória em Bergson}

Mas como ocorre, em Bergson, esse processo de "voltar-se para dentro"? Bergson, em Matéria e Memória chama de imagem tudo aquilo que aparece "no sentido mais vago em que se possa tomar essa palavra" (2010, p. 11). Imagem como a própria expressão do movimento de um universo acentrado e pré-humano de pura luz - em que tudo vibra. Nesse primeiro momento, todas as imagens agem e reagem, umas sobre as outras, em todas as suas faces. Num segundo momento, no conjunto do mundo material, surge uma imagem especial - que Bergson chama de "meu corpo". O "meu corpo" é "uma imagem que atua como as outras imagens, recebendo e devolvendo movimento" (2010, p.14). Contudo, a atuação dessa imagem especial é diferente, pois, "parece escolher, em certa medida, a maneira de devolver o que recebe" (2010, p. 14). Esse momento de escolha e hesitação é responsável por provocar um intervalo entre a ação e a reação. Uma espécie de retardo do movimento que permite que o tempo se insira na matéria. Aí nasce a memória.

"Meu corpo" com posse do intervalo tem tempo de acolher e escolher de que maneira irá devolver o movimento. Nesse momento, a percepção não se prolonga em reação necessária - como acontece nos organismos rudimentares, por exemplo, onde a reação não se pode fazer esperar e "o tocar é passivo e ativo ao mesmo tempo" (2010, p. 28) - mas tem tempo de colher, organizar e selecionar o movimento novo. Percebe, sente e age e não apenas percebe e age. "Meu corpo" então opera como um "centro de ação" (2010, p. 14) capaz de isolar certas excitações - aquilo que lhe interessa, aquilo que lhe é útil - ao mesmo tempo em que deixa que o que lhe é indiferente o atravesse.

\footnotetext{
Nietzsche nos fala de "interiorização dos instintos" à medida que compara o homem aos outros animais, determinando esta interiorização como o momento em que nós procuramos nós diferenciar das outras bestas da natureza. Bergson, por sua vez, nos fala de um "voltar-se para dentro" que cria o que ele chama de "centros de indeterminação", que são, a rigor, toda forma de vida, desde o mais simples protozoário. Nós homens seríamos o mais complexo desses centros, dessas zonas de indeterminação (GUÉRON, 2011, p. 136).
}

Diante da totalidade do mundo, o homem percebe sempre "menos" do que há de fato. A percepção é subtrativa, subjetiva, de certa forma "pobre" (BERGSON, 2010, p. 36). Nossa percepção consciente o tempo todo enquadra e escolhe com quem ou com o que vamos interagir. Esse subjetivismo, essa escolha, segundo Bergson, nasce da memória e a memória nasce justamente do intervalo, do hiato entre a ação e a reação.

São nossas lembranças que nos influenciam a ver no todo aquilo de que necessitamos. É nossa memória que nos faz ver no mundo "menos" do que há de fato. Ao andarmos por uma floresta com pouquíssimo conhecimento sobre botânica, pouco nos detemos para observar seja lá o que for, ou seja, pouco percebemos. Passamos reto e tudo parece igualmente verde. Do contrário, se nossa memória tivesse formado imagens e consciência sobre botânica, estaríamos bombardeamos por informações de todos os lados e uma planta específica dispararia lembranças e afetos.

As lembranças entram então em cena como uma espécie de filtro aos estímulos oferecidos, orientando as etapas de recebimento, retenção e transmissão dos movimentos. Nesse sentido, o ato de perceber não seria mais do que uma ocasião de lembrar, pois "não há percepção que não esteja 
impregnada de lembranças" (BERGSON, 2010, p. 30). As memórias estão misturadas ao nosso corpo quando percebemos, elas são "aquilo que devemos extrair inicialmente da percepção para reencontrar a pureza da imagem" (BERGSON, 2010, p. 60).

A filosofia de Bergson destrona uma tese bem presente no senso comum: a de que o passado não volta jamais - pois não tem existência real - e que o presente é tudo o que temos - pois tem existência real. Todavia, estar presente, para Bergson, tem a ver com experiências passadas. $\mathrm{O}$ presente (percepção) e o passado (lembrança) estão inteiramente interligados e coexistem - são contemporâneos - graças ao trabalho da memória. Bergson diz:

O que é para mim, o momento presente? É próprio do tempo decorrer; o tempo já decorrido é o passado, e chamamos presente o instante em que ele decorre. Mas não se trata aqui de um instante matemático. Certamente há um presente ideal, puramente concebido, limite indivisível que separaria o passado do futuro. Mas o presente real, concreto, vivido, aquele a que me refiro quando falo de minha percepção presente, este ocupa necessariamente uma duração. Onde portanto se situa essa duração? Estará aquém, estará além do ponto matemático que determino idealmente quando penso no instante presente? Evidentemente está aquém e além ao mesmo tempo, e o que chamo "meu presente" estende-se ao mesmo tempo sobre meu passado e sobre meu futuro (BERGSON, 2010, p. 161).

O presente é o inapreensível, é o que deixa de ser a todo instante, é o que decorre, é o que desliza e se esvai como "areia entre os dedos", mudando, passando sempre. Enquanto isso, o passado, é aquilo que é, que nunca deixa de ser. Ele é a própria condição de existência dos seres. Como diria Pelbart (2007, p. 36), "o passado é o único que é rigorosamente falando. Ainda que inútil, inativo, impossível, o passado é o em-si do ser, contrariamente ao presente, que, este sim, se consome e se coloca fora de si. O presente é o que constantemente já era, o passado o que constantemente já é".

A memória, segundo Bergson, sobrevive de duas diferentes maneiras: uma enquanto experiência vivida e outra enquanto reservatório de lembranças. A primeira, adquirida pela repetição de um esforço (movimentos automáticos), seria mais útil do que a segunda e teria como tarefa orientar a inteligência e o corpo a realizar suas funções de costume, nos auxiliando a agir e a viver. Antes hábito do que memória, formaria "o conjunto de mecanismos inteligentemente montados que asseguram uma réplica conveniente às diversas interpelações possíveis" (2010, p. 176-177).

A outra seria a memória por excelência, extensiva a consciência, capaz de armazenar todo o passado, mesmo sem pretensão de utilizá-lo. Ela reteria e alinharia "uns após outros todos os nossos estados à medida que eles se produzem dando a cada fato seu lugar e consequentemente marcandolhe a data" (2010, p. 177). Registraria "sob forma de imagem-lembrança, todos os acontecimentos de nossa vida cotidiana à medida que se desenrolam" (2010, p. 88). Para acessá-la seria preciso se abster da ação presente, dar valor ao inútil, sonhar.

Bergson deixa claro em muitos momentos de Matéria e Memória que não é no cérebro que as lembranças se conservam. O cérebro não é um recipiente de lembranças como pensavam os materialistas, mas um "instrumento de ação" (2010, p. 79). A condição da memória não reside num estado cerebral, pois o cérebro é pura objetividade, matéria e necessidade, e, a memória, pelo contrário, é espírito e liberdade. $O$ cérebro seria uma espécie de "central telefônica" que converteria os estímulos em procedimentos práticos. Uma imagem como as outras e nunca "reservatório de lembranças". Bergson (2010, p. 13) diz que "é o cérebro que faz parte do mundo material, e não o mundo material que faz parte do cérebro". Por isso as lembranças não desaparecem quando o cérebro sofre lesões. O que há é um impedimento da atualização, um bloqueio no órgão responsável por 
efetuar a comunicação ou fazer aguardar. Bergson analisa uma série de doenças do reconhecimento para chegar à conclusão que "não há nem pode haver no cérebro uma região onde as lembranças se fixem e se acumulem. A pretensa destruição das lembranças pelas lesões cerebrais não é mais que uma interrupção do progresso contínuo através do qual a lembrança se atualiza" (2010, p. 146).

Apreender o passado é apreendê-lo lá onde ele está, isto é, em si mesmo e não em nós, na nossa consciência, em algum lugar do nosso cérebro, como se existisse uma "caixa de lembranças". Devemos admitir então que há um passado que nunca deixa de ser, um passado em geral, como que um elemento ontológico - condição de passagem de todo presente particular. Essa totalidade do passado, esse passado em geral, que se conserva e que não pode ser atualizada em sua integralidade, Bergson chama de "lembrança pura": lembrança que coexiste virtualmente com cada presente e consigo mesmo. Por ser virtual, "continua presa ao passado por suas raízes profundas" (2010, p. 156) e, só se atualiza e toca o presente, ganhando uma data, quando é materializada pela lembrança-imagem. " $\mathrm{A}$ lembrança pura, certamente independente de direito, não se manifesta normalmente a não ser na imagem colorida e viva que a revela" (2010, p. 156). A lembrança pura é apenas a lembrança em vias de atualização, daí a sua virtualidade. "Tão logo se transforma em imagem, o passado deixa o estado de lembrança pura e se confunde com uma certa parte de meu presente. A lembrança atualizada em imagem difere assim profundamente dessa lembrança pura" (2010, p. 163).

Em outras palavras, o homem jamais consegue atualizar a totalidade das lembranças, assim como, jamais consegue resgatar essa memória "tal qual". Pensar o processo de reconstituição do passado sob o signo da integralização e objetividade é uma ilusão. $O$ passado não pode ser descrito de maneira factual e não pode ser recuperado em sua integralidade. Temos que admitir que por mais que o passado se conserve em sua totalidade, ele só pode ser atualizado enquanto "imagem". $\mathrm{O}$ processo de atualização do passado, ao qual a "lembrança pura" bergsoniana (virtual) se torna "imagem-lembrança" (atual) é "suja". Nunca vemos o passado com óculos limpos.

\section{Nem Funes, o memorioso, nem a besta que pasta no campo - considerações finais}

A força ativa do esquecimento, em Nietzsche, garante tanto um corpo saudável como põem em cheque a acumulação obsessiva do passado realizada pelo historicismo. Nietzsche $(2014$, p. 45) considera uma ilusão e um erro a pretensão positivista de uma ciência histórica que se diz neutra e objetiva. Ele diz: "A história na medida em que está a serviço da vida [...] nunca pode nem deve se tornar uma ciência pura, como a matemática [...]. $\mathrm{O}$ excesso de história destrói e degenera a vida, degenerando, por fim, a própria história". O historiador que pusesse em prática essa pretensão de reprodução fidedigna do que "foi" não passaria de um ingênuo que chama de "objetividade medir as opiniões e os fatos passados a partir das opiniões difundidas no momento" (2014, p. 89). O remédio para esse historicismo é o que Nietzsche (2014,p. 142) chama de a-histórico, ou seja, "a força de poder esquecer e se fechar em um horizonte delimitado" como os animais.

Todavia, aproximar o homem de sua condição animal não tem o sentido de "se tomar por" animal. Podemos arriscar pensar o a-histórico como o devir-animal e o devir-criança que afetam e contagiam o homem. Não quero dizer com isso que se trata de imitar um animal ou regredir a um estágio infantil. Como define Deleuze e Guattari (1997) devir não é tomar-se, assemelhar-se, ajustarse ou querer ser como.

A questão ‘o que você está se tornando?’ é particularmente estúpida. Pois à medida que 
alguém se torna, o que ele se torna muda tanto quanto ele próprio. Os devires não são fenômenos de imitação, nem de assimilação, mas de dupla captura, de evolução não paralela, núpcias entre dois reinos" (DELEUZE, PARNET, 1998, p. 10).

A lembrança então não seria algo enrijecido, cristalizado, mas um bloco de devires que se opõe a memória molar do passado "tal qual". Linhas, fios, blocos e não pontos. Ainda de acordo com Deleuze e Guatarri (1997, p. 92): “O devir é um movimento pelo qual a linha libera-se do ponto, e torna os pontos indiscerníveis [...]. O devir é uma anti-memória". Se o devir-animal e o devir-criança do homem podem ajuda-lo na manutenção de uma certa harmonia psíquica, o cérebro, a partir das formulações de Bergon em Matéria e Memória, pode ser um mecanismo fundamental para nos ajudar a fugir dos extremos. Mas o que isso quer dizer?

O cérebro, em Matéria e Memória, aparece como esse mecanismo que pode favorecer o equilíbrio entre memória e esquecimento. Funcionando como um intermediário que "contribui para chamar de volta a lembrança útil, porém mais ainda para afastar provisoriamente todas as outras" (BERGSON, 2010, p. 208). Em vez de "reservatório de lembranças", como pensavam os materialistas, órgão de atenção à vida. Em outras palavras, o cérebro seria um mecanismo fundamental no processo evolutivo, na medida em que atualizaria e permitiria que apenas uma pequena parte desse "passado em geral" se torne consciente.

Mas por qual razão se torna importante recalcar a maior parte de nossas lembranças? Devido a nossa necessidade mais básica de sobrevivência. Em momentos, por exemplo, onde há um afrouxamento dos vínculos sensório-motores, onde há um relaxamento da tensão do sistema nervoso, muita coisa vem à tona, imagens obscurecidas, como nos momentos em que dormimos. "É um fato de observação comum a 'exaltação' da memória em certos sonhos e em certos estados sonambúlicos. Lembranças que se acreditavam abolidas reaparecem com uma exatidão impressionante: revivemos em todos os detalhes cenas de infância inteiramente esquecidas" (BERGSON, 2010, p. 181).

Bergson, assim como Nietzsche, está também em busca de um corpo saudável. Em muitos momentos de Matéria e Memória ele fala de "equilíbrio", de "atenção à vida". Em busca de uma vivência que não fosse "impulsiva" - como aquela de quem vive no presente puro, respondendo a uma "excitação através de uma reação imediata que a prolonga" (2010, p. 179), como os animais inferiores - nem "sonhadora" - como aquela de quem "vive no passado por mero prazer, e no qual as lembranças emergem à luz da consciência sem proveito para a situação atual" (2010, p. 179). Nem ser como Funes, nem como a besta que pasta no campo. Lembrar, mas também saber esquecer para conseguir viver o presente. 


\section{Referências}

ASSMANN, Aleida. Espaços da recordação: formas e transformações da memória cultural. Campinas, SP: Editora da Unicamp, 2011.

BERGSON, H. Matéria e Memória: ensaio sobre a relação do corpo com o espírito. Trad. Paulo Neves. $4^{\circ}$ Ed. São Paulo: Martins Fontes. 2010.

BORGES, Jorge Luís. Funes, o memorioso. In: Ficções. São Paulo: Globo, 1995.

DELEUZE, Gilles; PARNET, Claire. Diálogos. Trad. de Eloísa Araújo Ribeiro. São Paulo: Escuta, 1998.

DELEUZE, Gilles; GUATTARI, Felix. Mil Platôs: capitalismo e esquizofrenia. v. 4. São Paulo: 34, 1997.

GAGNEBIN, Jeanne. Marie. Lembrar, escrever, esquecer. São Paulo: 34, 2006.

GUÉRON, R. Da imagem ao clichê, do clichê a imagem; Deleuze, cinema e pensamento. Rio de janeiro: NAU Editora. 2011.

NIETZSCHE, Friedrich. A genealogia da moral. Trad. Mário Ferreira dos Santos. Petrópolis: Vozes, 2013.

NIETZSCHE, Friedrich. Sobre a utilidade e a desvantagem da história para a vida. Trad. André Luís Mota Itaparica. São Paulo: Hedra, 2014.

NIETZSCHE, Friedrich. A gaia ciência. Trad. Inês A. Lohbauer. São Paulo: Martin Claret, 2016.

NIETZSCHE, Friedrich. O crepúsculo dos ídolos; ou, a filosofia a golpes de martelo. Trad. Edson Bini e Márcio Pugliesi. São Paulo: Hemus, 1976.

PELBART, Peter Pal. O tempo não-reconciliado. Perspectiva (coleção estudos; 160 / dirigida por J. Guinsburg). São Paulo. 2007.

SELIGMANN-SILVA, Márcio (org.). História, Memória, Literatura. O testemunho na era das catástrofes. Campinas, Editora da UNICAMP, 2003.

SULEIMAN, Susan. Crises da memória e a Segunda Guerra Mundial. Trad. Jacques Fux e Alcione Cunha da Silveira. Belo Horizonte: Editora UFMG, 2019.

TARKOVSKI, A. Esculpir o tempo. Trad. Jefferson Luiz Camargo. 2 ed - São Paulo: Martins Fontes. 1990.

Autor(a) para correspondência / Corresponding author: Ludymylla Maria Gomes de Lucena. ludymyllalucena@gmail.com 